Dicle Tıp Dergisi / Dicle Med J (2019) 46 (4) : 641 - 647

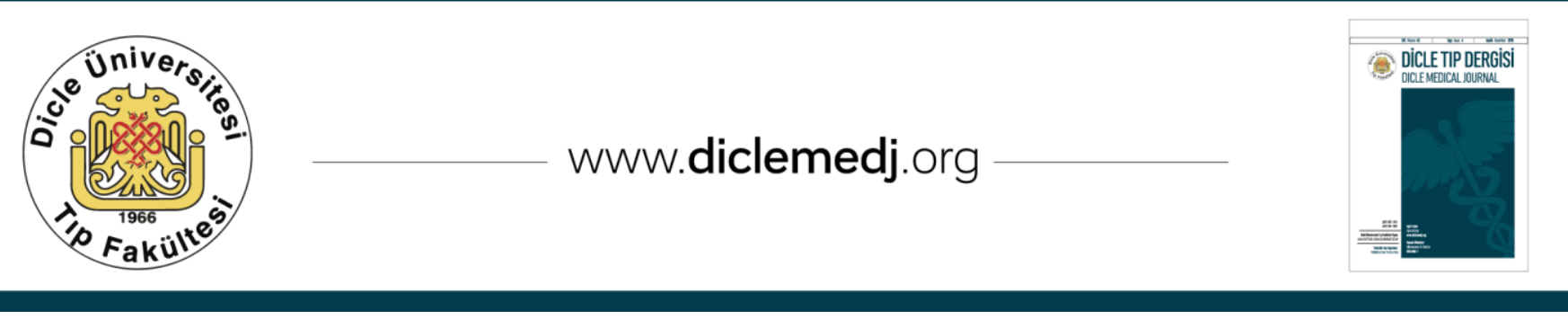

Özgün Araștırma / Original Article

\title{
Ventilatör İlişkili Pnömoni Hastalarından İzole Edilen Mikroorganizmaların Antimikrobiyal Duyarlılıkları
}

\author{
Veysel Toksöz'1, Mustafa Yılmaz² \\ 1 Fırat Üniversitesi Tıp Fakültesi Mikrobiyoloji Anabilim Dalı Başkanlı̆̆ı Merkez, Elazığ, Türkiye ORCID: 0000-0002-2117-0653 \\ 2 Fırat Üniversitesi Tıp Fakültesi Mikrobiyoloji Anabilim Dalı Başkanlığı Merkez, Elazığ, Türkiye ORCID: 0000-0003-4385-6733
}

Geliş: 25.03.2019; Revizyon: 23.07.2019; Kabul Tarihi: 24.09.2019

$\ddot{\mathbf{O z}}$

Amaç: Ventilatör ilişkili pnömoni(VİP), invaziv mekanik ventilasyon uygulanan hastalarda gelişen ve yoğun bakım ünitelerinde sık karşılaşılan, mortalite oranı yüksek hastane enfeksiyonudur. Klinik olarak ventilatör ilişsili pnömoni tanısı almış hastalarda solunum yolu materyalinde üreyen bakteriler ve antibiyotiklere duyarlılıklarını belirlemeyi amaçladık.

Yöntemler: Çalışmada, yoğun bakım ünitelerinde klinik olarak ventilatör ilişkili pnömoni tanısı konulan 50 hastadan alınan endotrakeal aspirat (ETA) örnekleri \%5 koyun kanlı agar (Oxoid, Hampshire, ENGLAND) ve "Eosin Methylene Blue" (EMB) (Oxoid, Hampshire, ENGLAND) agarına ekildi. Plaklar $37^{\circ} \mathrm{C}^{\prime}$ de $18-24$ saat inkübe edildi; saf kültür halinde $\geq 100000 \mathrm{cfu} / \mathrm{ml}$ üreyen plaklar çalışmaya dahil edildi. İzole edilen etkenlerin tanımlanması ve antimikrobiyal duyarlılıkları konvansiyonel yöntemler ve Phoenix Diagnostic System (Sparks, MD, USA) sistemi ile araştırılmıştır.

Bulgular: Ventilatör ilişkili pnömoni olgularında; Acinetobacter baumannii (A. baumannii) \%42, Klebsiella pneumoniae(K.pneumoniae) \%26, Pseudomonas aeruginosa(P.aeruginosa) \%20, Serratia marcescens(S.marcescens) \%4, \%2'şer oranlarla da Streptococcus pneumoniae(S.pneumoiae), Enterobacter spp, Staphylococcus aureus(S.aureus) ve Stenotrophomonas maltophilia(S.maltophilia) izole edilmiştir. A. baumannii izolatlarının 42'sinin hepsinin (\%100) seftazidim, imipenem, meropenem, piperasilin-tazobaktam ve sefepime duyarlı olmadığı saptanmıştır. K.pneumoniae izolatlarında gentamisin duyarlılığı \%85, trimetoprim-sulfametaksazol duyarlılığı \%62 olarak saptanmıştır. P.aeruginosa izolatlarında ise piperasilin-tazobaktam'a \%10 oranında duyarlılık tespit edilmiştir.

Sonuç: Ampirik tedavide kullanılacak antibiyotiklerin ünitenin mikrobiyolojik flora ve antibiyotik duyarlılığına göre yönlendirilmesi, etken izolasyonu sonrasında ise; tedavinin antibiyotik duyarlılık sonucuna göre dar spektrumlu antibiyotiklerle modifiye edilmesi gerektiği kanaatine varılmıştır.

Anahtar kelimeler: Ventilatör ilişkili pnömoni, antimikrobiyal duyarlılık, enfeksiyon 


\title{
Antimicrobial Susceptibility of Microorganisms Isolated from Ventilator-Associated Pneumonia Patients
}

\begin{abstract}
Objective: Ventilator-associated pneumonia (VAP) is a high-mortality rate nosocomial infection that frequently develops in invasively mechanically ventilated patients in intensive care units. The aim of this study was to determine the bacterial proliferation in patients with VAP and as certain their susceptibility profiles to the antibiotics.

Methods: In this study, endotracheal aspirate (ETA) samples obtained from 50 patients diagnosed as ventilatorassociated pneumonia in intensive care units on 5\% sheep blood agar (Oxoid, Hampshire, ENGLAND) and "Eosin Methylene Blue" (EMB) (Oxoid, Hampshire, ENGLAND) agar were sown. Plates were incubated at 37 ${ }^{\circ} \mathrm{C}$ for $18-24$ hours; plates grown in pure culture $\geq 100000 \mathrm{cfu} / \mathrm{ml}$ were included in the study. Antimicrobial susceptibilities of the detected agents were investigated in Phoenix Diagnostic System (Sparks, MD, USA).

Results: In ventilator-associated pneumonia cases; Acinetobacter baumannii (A. baumannii) 42\%, Klebsiella pneumoniae (K.pneumoniae) 26\%, Pseudomonas aeruginosa (P.aeruginosa) 20\%, Serratia marcescens (S.marcescens) 4\%, Streptococcus pneumoniae (S. Pneumoiae), Enterobacter spp, Staphylococcus aureus (S.aureus) and Stenotrophomonas maltophilia (S.maltophilia) were isolated. It was found that A. baumannii strains were not (100\%) sensitive to ceftazidime, imipenem, meropenem, piperacillin-tazobactam and cefepime. The susceptibility of Klebsiella strains to Gentamicin was $85 \%$ and trimethoprim-sulfamethoxazole was $62 \%$. Besides, it was found that P.aeruginosa strains were $10 \%$ susceptible to piperacillin-tazobactam.

Conclusion: It was concluded that, antibiotics which will be used in ampirical treatment should be selected according to the microbiological flora and antibiotic susceptibility of the intensive care unit sandafter the isolation of the bacteria, the treatment should be replaced with narrow spectrum antibiotics according to the antibiotic susceptibility results.
\end{abstract}

Keywords: Ventilator-associated pneumonia, antimicrobial susceptibility, infection.

\section{GíRiş}

Pnömoniler, mortalite yönünden nozokomiyal enfeksiyonlar arasında ilk sırada yer alması ve hastaneye yatışı gerektiren hastalıkların önde gelenlerinden olması nedeniyle hem gelişmiş hem de gelişmekte olan ülkelerde ciddiyetini sürdürmektedir ${ }^{1}$. Nozokomiyal pnömoni, gelişimi yönünden en yüksek riske sahip hasta grubu entübe edilen, mekanik ventilatöre bağlanan ve çoğunlukla yoğun bakım üniteleri (YBÜ)'inde yatmakta olan hastalar oluşturmaktadır ${ }^{2}$ Bununla birlikte, trakeostomisi olan veya entübe edilen ve pnömoni tanısının konduğu günden önceki 48 saat içinde kalan dönemde solunuma destek olmak veya kontrol etmek amaciyla bir mekanik ventilatöre bağlı olan hastalarda gelişen nozokomiyal pnömoni, ventilatör ilişkili pnömoni (VIP) olarak tanımlanmaktadır ${ }^{3}$.
Dünyada hastane kaynaklı pnömonilerin tüm hastane enfeksiyonlarının ortalama \%15'ini, ülkemizde yapılan çalışmalarda ise \%1130'unu oluşturduğu bildirilmektedir ${ }^{4}$. YBÜ'de ise VIP insidansı \%9-24 arasinda değişmektedir ${ }^{5}$.

Ventilasyon uygulanan hastalarin solunum sisteminde bakteri kolonizasyonuna sik rastlanmakta ve kolonizasyon sonrasinda enfeksiyon gelişme riski anlamlı olarak artmaktadır. Hastalığın patogenezinde; etkenlerin mikroaspirasyonu, orofaringeal ve trakeobronşiyal bakteri kolonizasyonu ile subglottiksekresyonların aralıklı drenajı rol oynamaktadır ${ }^{6}$.

VIPP tanısı için klinik ve radyolojik bulgular ön planda olmakla birlikte, mikrobiyolojik tanısal işlemler prognozun değerlendirilmesi, uygun tedavinin verilmesi açısından önemlidir ${ }^{7}$. Günümüzde tanısal yaklaşım yöntemlerinin 
değișik duyarlılık ve özgüllükleri nedeniyle altın standart kabul edilen bir yöntem henüz yoktur. Bununla beraber tanıda bronkoskopik ve non-bronkoskopik yöntemler kullanılmaktadır. Bronkoskopik yöntemler uygulanması zor, komplikasyonları fazla ve maliyetleri yüksek olan yöntemlerdir. Endotrakeal aspirasyon (ETA) ise; daha az invazif, kolay uygulanabilir, ucuz, komplikasyonları az ve her zaman kullanılabilecek bir yöntemdir ${ }^{1}$. Düşük spesifite ve yanlış pozitiflik oranının yüksek olmasına rağmen ETA kantitatif kültürünün invazif yöntemlere benzer şekilde ViP tanısında etkin olduğu gösterilmiştir ${ }^{8-9}$.

Bu çalışmada, YBÜ'de ViP tanısı alan hastaların ETA örneklerinden izole edilen bakteriler ile bunların çeşitli antibiyotiklere karşı duyarlılıkları araştırılmıştır.

\section{YÖNTEMLER}

Firat Üniversitesi Tıp Fakültesi yeni doğan ve dahili yoğun bakım ünitelerinde tedavi gören, VIP ön tanılı hastalardan alınan ve merkez laboratuvarına gönderilen ETA örneği ile çalışılmıştır.

\section{Etik Kurul Onayı}

Fırat Üniversitesi Tıp Fakültesi Klinik Araştırmalar Etik Kurulu Başkanlığı'nca 11.04.2013 tarih ve 01 nolu Etik Kurulu Kararı onayı alınarak 01.05.2013-01.05.2014 tarihleri arasında gerçekleştirilmiştir.

VIP ön tanılı hastalardan alınan ETA, Koyun Kanlı agar (Oxoid, Hampshire, ENGLAND) ve Eozin Metilen Blue agar (Oxoid, Hampshire, ENGLAND) besiyerlerine ekimleri yapıldı. Plaklar $37^{\circ} \mathrm{C}^{\prime}$ de $18-24$ saat inkübe edildi; saf kültür halinde $\geq 100000 \mathrm{cfu} / \mathrm{ml}$ üreyen plaklar çalışmaya dahil edildi. Gram boyama, lökosit ve bakteri açısından değerlendirildi. İzole edilen etkenlerin " Phoenix Diagnostic System (Sparks, MD, USA)" sisteminde tanımlanması ve antibiogramı $^{1}$ yapıldı. Üreyen bakterilerin antibiyotik duyarlılığı, Clinical and Laboratory
Standards Institute önerileri doğrultusunda değerlendirildi. Streptokoklar için hassasiyet kanlı agarda disk difüzyon yöntemiyle araştırıld $1^{10}$.

S. pneumoniae tanımlanmasında katalaz testi ve optokin duyarlılığ incelendi. Kalite kontrol suşları olarak S.aureus ATCC 25923, E.coli ATCC 25922, E.faecalis ATCC 29212, P.aeruginosa ATCC 27853 kullanıldı.

Stafilokoklarda metisilin duyarlılığını saptamada sefoksitin disk difüzyon testi kullanıld ${ }^{11}$.

Elde edilen sonuçlar bilgisayar ortamında paket programlar kullanılarak Ki-kare testine göre veri analizleri yapılmış ve $\mathrm{P}<0.05$ olan değerler anlamlı kabul edilmiştir. Hastalarda tespit edilen etkenler gruplandırılmış, bu etkenlerin antibiyotik dirençleri ise \% ifadeler, grafik ve tablolarla görselleștirilmiștir.

\section{BULGULAR}

Yoğun bakım ünitesinde invaziv mekanik ventilasyona bağlı pnömoni gelişen hastalardan alınan 50 örnekten 21'i(\%42) kadın 29'u (\%58) ise erkek hastalara ait idi. Bu hastalarm 28'i (\%56) yeni doğan ve bebek yaşta (0-2 yaş), 22 'si (\%44) ise 17-85 yaş aralığındaydı. Hastalardan izole edilen bakterilerin sayı ve yüzdeleri Tablo I'de verilmiştir.

Tablo I: İzole edilen mikroorganizmaların dağılımı

\begin{tabular}{|lcc|}
\hline & Sayı (n) =50 & Yüzde (\%) \\
Acinetobacter baumanii & 21 & 42 \\
Klebsiella pneumoniae & 13 & 26 \\
Pseudomona saeruginosa & 10 & 20 \\
Enterobacter spp & 1 & 2 \\
Streptococcus pneumoniae & 1 & 2 \\
Staphylacoccus aureus & 1 & 2 \\
Stenotrophomonas maltophilia & 1 & 2 \\
Serratia marcescens & 2 & 4 \\
Toplam & 50 & 100 \\
\hline
\end{tabular}


Tablo II: VIP Olgularından izole edilen Klebsiellapneumonia, Pseudomonasaeruginosa, Acinetobacterbaumaniiizolatlarının antibiyotiklere duyarlılık tablosu

\begin{tabular}{|c|c|c|c|c|c|c|}
\hline & \multicolumn{2}{|c|}{$\begin{array}{c}\text { Klebsiella } \\
\text { pneumonia } \\
(n)=13\end{array}$} & \multicolumn{2}{|c|}{$\begin{array}{c}\text { Pseudomon } \\
\text { asaerugino } \\
\text { sa }(n)=10\end{array}$} & \multicolumn{2}{|c|}{$\begin{array}{c}\text { Acinetobo } \\
\text { cterbaum } \\
\text { anii }(n)= \\
21\end{array}$} \\
\hline \multirow{2}{*}{ Antibiyotikler } & \multicolumn{2}{|c|}{ Duyarlı } & \multicolumn{2}{|c|}{ Duyarlı } & \multicolumn{2}{|c|}{ Duyarlı } \\
\hline & Sayı & $\%$ & Sayı & $\%$ & Sayı & $\%$ \\
\hline Ampisilin & 6 & 46 & - & - & - & - \\
\hline Sefazolin & 10 & 77 & - & - & - & - \\
\hline Gentamisin & 11 & 85 & 2 & 20 & 1 & 4 \\
\hline Amikasin & - & - & 8 & 80 & 2 & 10 \\
\hline Siprofloksasin & - & - & 6 & 60 & 1 & 4 \\
\hline $\begin{array}{l}\text { Amoksisilin- } \\
\text { Klavulanate }\end{array}$ & 13 & 92 & - & - & - & - \\
\hline $\begin{array}{l}\text { Trimethoprim- } \\
\text { Sulfametoksazol }\end{array}$ & 8 & 62 & - & - & 6 & 29 \\
\hline Sefuruksim & 11 & 85 & - & - & - & - \\
\hline Seftriakson & 11 & 85 & - & - & - & - \\
\hline $\begin{array}{l}\text { Piperasilin- } \\
\text { Tazobaktam }\end{array}$ & 10 & 77 & 1 & 10 & - & - \\
\hline Aztreonam & 9 & 69 & 3 & 30 & - & - \\
\hline Sefepime & 9 & 69 & 2 & 20 & - & - \\
\hline İmipenem & - & - & 2 & 20 & - & - \\
\hline Meropenem & - & - & 3 & 30 & - & - \\
\hline Sefoksitin & 13 & 92 & - & - & - & - \\
\hline Levofloksasin & - & - & 3 & 30 & - & - \\
\hline Seftazidim & - & - & 6 & 60 & - & - \\
\hline Ampisilin-Sulbaktam & - & - & - & - & 1 & 4 \\
\hline
\end{tabular}

İzole edilen tek S.pneumoniae izolatının penisiline dirençli olduğu saptandı.

İzole edilen tek S.aureus izolatının metisilin dirençli (MRSA) olduğu görüldü.

S. maltophilia izolatı, levofloksasin ve trimetoprim-sulfametoksazola duyarlıydı.

A.baumanii ve $K$. pneumoniae P.aeruginosa izolatlarının antibiyotik duyarlılık sonuçları Tablo II'de verilmiştir.
S.marcescens ve Enterobacter spp. İzolatları karbapenemlere duyarlı olarak saptandı.

Hasta yaş ortalaması 23,22 olarak belirlenmiş ve 0-2 yaş ile 17-85 yaş arası ile VİP gelişimi arasinda istatistiksel ( $p>0.602)$ bir anlam saptanmamıștır.

\section{TARTIŞMA}

Ventilatörle ilișkili pnömoni; YBÜ'nde, 48 saatten uzun süreli entübe edilmiş hastalarda gelişen, nozokomiyal enfeksiyonlar içinde önemli morbidite ve mortalite nedeni olan akciğer parankim dokusu enfeksiyonudur ${ }^{12}$.

VIP etiyolojisinde yer alan mikroorganizmalar; hastaneden, hastanın yattığı yoğun bakımın mikrobiyal florasından, hastanın kendi florasından, diğer hastalardan, ziyaretçilerden ve hastane çalışanlarından kaynaklanabilmektedir ${ }^{13}$. Pnömoniye neden olan etkenlerin dağılımı da, farklı hastaneler, farklı hastane popülasyonu ve uygulanan tanısal yöntemler nedenleri ile farklıklar göstermektedir. $\mathrm{Bu}$ nedenle her hastanenin kendi mikrobiyal florasını ve duyarlılık profilini belirlemesi ve ampirik tedavide buna göre karar vermesi gereklidir ${ }^{14}$.

Günümüzde VİP tanısında kullanılan mikrobiyolojik yöntemlerinden biri endotrakealaspirat (ETA) örneğinin bakteriyolojik incelenmesidir. Duyarlılık \% 38100, Özgüllük \%14-100 aralığında değişmekle birlikte ETA kantitatif kültürü VIP tanısında kullanılmaktadır ${ }^{9,15-20 .}$

Marquetteve ark. 1995 yılında yaptığı çalışmada akciğer dokusunun histolojik incelenmesini altın standart olarak kabul edilmiş ve ETA, korumalı fırça örneği (PSB), Bronkoalveolar lavaj (BAL) örneklerinin kantitatif kültürü ile kıyaslanmıştır. Bu yöntemler arasında benzer duyarlılık ve özgüllük tespit etmişlerdir. Son zamanlarda yapılan çalışmalar ETA kantitatif kültürünün 
invaziv teknikler kadar kullanılabilir bir yöntem olduğu vurgulanmıștır ${ }^{15,16,21,22}$.

Yılmaz ve Ark.2000 yılında yaptıkları çalışmada 48 saatten daha uzun süre izlenen yoğun bakım ünitesindeki 252 hastada 211 enfeksiyon atağı saptamıştır. Hasta yaşıyla VİP gelişimi arasında istatistiksel olarak bir anlam ( $>0.506)$ saptanamamıştır ${ }^{23}$. Çalışmamızda 21'i bayan 29'u erkek olmak üzere mekanik ventilasyon ihtiyacı duyan ve klinik VİP tanılı hastaların yaş ortalaması 23,22 olarak belirlenmiş ve hasta yaşıyla VIP gelişimi arasında diğer çalışmalarla uyumlu olarak istatistiksel ( $p>0.602)$ bir anlam saptanamamıștır.

Çalışmalarda VíP etkenlerinin dağılımı sırayla P.aeruginosa, Acinetobacter spp, K.pneumoniae başta olmak üzere Gram-negatif bakteriler olup, son yıllarda S.aureus bașta olmak üzere Gram-pozitif etkenlerin sıklığında da artış bildirilmektedir[4-7]. Doksanlı yıllarda yaygin etkenler, $\% 27 \quad$ P.aeruginosa, $\% 23$ K.pneumoniae, \%20 Acinetobacter spp. ve \%12 MRSA izole edilirken,200'li yıllarda da aynı etkenler ilk sıraları almıștır. 2004 yılında Dikmen ve ark. VIP tanılı hastalarda sirasiyla A.baumannii $(\% 37,8)$, P.aeruginosa $(\% 13,5)$ ve MRSA $\quad(\% 10,8) \quad$ saptamışlardır[5-24]. çalışmamızda A.baumannii (\%42), K.pneumoniae (\%26) P.aeruginosa (\%20) izole edilmiş olup ilk sıralardaki etkenlerin önemini koruduğu ancak A.baumannii in yüksek oranda birinci sırada yer aldığı görülmektedir.Özellikle çoklu antibiyotik direnci olan Acinetobacter spp enfeksiyonları günümüzde önemli bir problemdir.

Acinetobacter spp'nin epidemiyolojisininin araştırıldığı bir çalışmada 41 Acinetobacter suşunun $26(\% 63,5)$ 'sının imipeneme duyarlı olmadığ $\quad$ saptanmıştır ${ }^{25}$. Çalışmamızda imipeneme duyarlı Acinetobacter suşu tesbit edilmemiştir.Yapılan çalışmalar imipenem duyarlılığının azaldığını bildirmektedir. Entübe hastaların artması, imipenem, aminoglikozit ve kinolon kullanımının yaygınlaşması, ko- trimoksazol, tetrasiklin gibi antibiyotiklerin az kullanılıyor olması artan direncin nedenleri arasında gösterilmektedir ${ }^{5-25}$.

A.baumannii 'nin diğer antibakteriyel ajanlar içinde duyarlılıklarında önemli oranda düşüşler tesbit edilmiştir. Suşların hepsinin, seftazidim, imipenem, meropenem, piperasilin-tazobaktam ve sefepim'e duyarlı olmadığı dolayısıyla dirençli olduğu, ampisilin-sulbaktam ve siprofloksasine $\% 5$, amikasine $\% 10$, trimetoprim-sulfametoksazol \%30 oranında duyarlı olduğu görülmüştür. A.baumannii'nin hastanemiz yoğun bakım ünitesinde tedavisi güç bir etkendir. Mikroorganizma ile mücadelede yeni arayışlar gerekmektedir.

Sonuç olarak; YBÜ'de geniş spektrumlu antibiyotiklerin yaygın kullanılması, çoklu dirençli bakteriyel enfeksiyonların artışına neden olmaktadır. Antibiyotik duyarlılık testlerinin sonuçları, ampirik tedavide kullanılabilecek Antibiyotik sayısının giderek azaldığını göstermektedir. YBÜ'de yatan ve mekanik ventilatöre bağlı hastalar ViP gelișimi açısından yakından izlenmeli, koruyucu önlemlere özen gösterilmeli ve tedavinin uygun biçimde yapılabilmesi için her hastane kendi etkenlerini ve antibiyotik duyarlılık profilini belirlemelidir.

\section{TESEKKÜR}

Tez çalışmalarım boyunca, emeğini, bilgisini ve desteğini sonuna kadar benden esirgemeyen, yanında çalışmaktan onur duyduğum ve ayrıca tecrübelerinden yararlanırken göstermiș olduğu hoşgörü ve sabırdan dolayı değerli hocam Prof. Dr. Mustafa YILMAZ'a teşekkürlerimi sunarım.

Bir aile gibi olduğum laboratuvarda beraber çalıştığım mesai arkadaşlarıma, örneklerimi toplarken bana destek oldukları için Dr. Murat TÜRKEN'e, Yüksek Lisans ve Doktora öğrencisi arkadaşlarıma, tezimi hazırlarken faydalandığım Tıbbi Mikrobiyoloji Anabilim Dalı literatürünün oluşumunda geçmişten 
günümüze kadar katkıda bulunmuş tüm bilim insanlarına teşekkürlerimi borç bilirim.

Çıkar Çatışması Beyanı: Yazarlar çıkar çatışması olmadığını bildirmişlerdir.

Finansal Destek: TF.13.33 projemize finasman desteklerinden dolayı Frrat Üniversitesi Bilimsel Araştırma Projeleri Koordinasyon Birimi (FÜBAP) tarafından desteklenmiştir. FÜBAP Teşekkür ederim.

Declaration of Conflicting Interests: The authors declare that they have no conflict of interest.

Financial Disclosure: TF.13.33 was supported by Firat University Scientific Research Projects Coordination Unit (FÜBAP) due to financial support.

\section{KAYNAKLAR}

1. Çelik D, Şahin YT, Ilgazlı A. Ventilatör iliş̧kili pnömoni tanısında bronkoskopik ve bronkoskopik olmayan yöntemlerin tanısal etkinliklerinin karşılaştırılması. Eurasian journal of pulmonology. 2006; 12: 95-101.

2. Bergmans DCJJ, Bonten MJM. Nosocomial pneumonia. Mayhall CG ed: Hospital Epidemiology and Infection Control. 3rd ed. Philadelphia: Lippincott, Williams \&Wilkins, 2004: 311-39.

3. Çetinkaya ŞY. Hastane kökenli pnömonilerde laboratuar yöntemlerinin akılcı kullanımı. Ankem Dergisi. 2005; 30: 28-32.

4. Şafak B, Çiftçi İH, Kıyıldı N. Ventilatör ilişskili pnömoni tanısında endotrakealaspirat kültürleri: 2004-2006 yılları sonuçları. Ankem Dergisi. 2007; 30: 81-5.

5. Dikmen Y, Aygün G, Öztürk R. Yoğun bakım ünitesinde ventilatörle ilișkili pnömonilerin değerlendirilmesi. Klimik Dergisi. 2004; 17: 117-9.

6. Demirdağ K, Cihangiroğlu M, et al. Mekanik ventilasyon desteği alan hastaların trakealaspirat örneklerinden izole edilen bakteriler ve antibiyotik duyarlılıkları. Klimik Dergisi. 2003; 16: 68-72.

7. Bayraktar B, Arslan Karabulut N, Bulut E, Şahin N. Yoğun bakım ünitesi hastalarından mini-BAL kültürü ile izole edilen ventilatörle ilişkili pnömoni etkenleri ve çeşitli antibiyotiklere duyarlılıkları. Türk Mikrobiyoloji Cemiyeti Dergisi. 2007; 37: 15-8.
8. Yahyaoğlu M. Ventilatör iliş̧kili pnömoni tanısında endotrakealaspiratkantitatif kültürü ile mini-BAL kantitatif kültürü arasındaki uyum. Uzmanlık tezi. İstanbul Eğitim Araştırma Hastanesi, İstanbul, 2006; 456.

9. Marquette $\mathrm{CH}$, Georges $\mathrm{H}$, Wallet F. Diagnostic efficiency of endotracheal aspirate with quantitative bacterial cultures in intubated patients with suspected pneumonia. Comparison with the protected specimen brush. American Review of Respiratory Disase1993; 148: $138-44$.

10. Gür D. Clinicaland Laboratory Standards Institute (CLSI). 18. Baskı. Ankara: Bilimsel Tıp Yayınevi. 2008: 100-18.

11. Haley RW, Culver DH, White JW et al. Theefficacy of infection surveillance and control programs in preventing nosocomial infections in US hospitals. American Journal of Epidemiology 1985; 121: 182-205.

12. Biberoğlu K. Ventilatör ilişskili pnömoniler. Yoğun Bakım Dergisi. 2001; 1: 98-105.

13. Ruiz M, Torres A, Ewig S. Non-invasive versus invasive microbial investigation in ventilatorassociated pneumonia: Evaluation of outcome. American Journal of Respiratoryand Critical Care Medicine. 2000; 162: 119-25.

14. Chastre J, Fagon JY. Ventilator associated pneumonia. American Journal of Respiratoryand Critical Care Medicine. 2002; 165: 867-903.

15. Marquette $\mathrm{CH}$, Copin MC, Wallet F. Diagnostic tests for pneumonia in ventilated patients: prospective evaluation of diagnostic accuracy using histology as a diagnostic gold standart. American Journal of Respiratoryand Critical CareMedicine. 1995; 151: 1878-88.

16. El-Ebiary M, Torres A, Gonzales J. Quantitative cultures of endotracheal aspiratfor the diagnosis of ventilator associated pneumonia. American Review Respiratory Disase. 1993; 148: 1552-7.

17. Sauaia A, Moore FA, Moore BE, et al. Diagnosing pneumonia in mechanically ventilated trauma patients: Endotracheal aspirate versus broncoalveolar lavage. Trauma. 1993; 35: 512-7.

18. Torres A, Martos A, Puiq de la Bellacasa JP. Specificity of endotracheal aspiration, protacted specimen brush, and broncoalveolar lavage in mechanically ventilated ptients. American Review Respiratory Disase. 1993; 147: 952-7. 
19. Jourdain B, Novara A, Joly-Guilloi ML. Role of quantitative cultures of endotracheal aspirates in the diagnosis of nosocomial pneumonia. American Journal of Respiratoryand Critical Care Medicine. 1995; 152: 241-6.

20. Cook D, Mandell L. Endotracheal aspration in the diagnosis of ventilator-associated pneumonia. Chest Journal. 2000; 117: 195-7.

21. Salata RA, Lederman MM, Shlaes DM. Diagnosis of nosocomiall pneumonia in intubated, intensivecare unit patients. American Review Respiratory Disase. 1987; 135: 426-62.

22. Fangio P, Rouquette V, Rousseau JM, Soullie B, Brinquin L. Diagnosis of ventilator associated pneumonia: Aprospective comparison of the telescoping plugged catheter with the endotracheal aspirate. Annales Françaises Anesthesie Reanimation. 2002; 21: 184-92.
23. Yılmaz G, Çaylan R, Ulusoy H, et al. Yoğun bakım ünitesinde izlenen ventilatörle ilișkili pnömonilerin değerlendirilmesi. Yoğun Bakım Dergisi. 2004; 4: 1317.

24. Uzel S, Özsüt $H$, Eraksoy $H$, et al. Yoğun bakım biriminde ventilatör ilișkili pnömoni etkeni olabilecek bakterilerin dağılımı ve antibiyotiklere duyarlılıkları. Klimik Dergisi. 1996; 9: 6-9.

25. Garnacho MJ, Ortiz LC, Fernandez HE. Acinetobacter baumannii ventilator-associated pneumonia: Epidemiological and clinical findings. Intensive Care Medicine. 2005; 31: 649-55. 